\title{
Process of a Territorial Energy Plan in an Isle
}

\author{
M. Martínez, A. Pulido, J. Romero, JC.Quintana, J. Cruz
}

Department of Electrical Engineering

E.T.S.I.I., Las Palmas de Gran Canaria University

Campus of Tafira - Edif. Ingeniería, 35017 Las Palmas de Gran Canaria (Spain)

Phone/Fax number:+0034 928451987, e-mail: mmartinez@die.ulpgc.es, apulido@die.ulpgc.es

\begin{abstract}
Several years ago Canary Islands have an Energy Plan PECAN, but that Plan was not fulfilled due to lack of land for the different infrastructures. It has been necessary to prepare an Territorial Plan for Energy Infrastructures of each isle, we try to present the procedure followed.
\end{abstract}

\section{Key words}

Teritorial Plan, Energy, Isles, environment, resources

\section{Introduction}

Island systems have a peculiarities that differentiate from the mainland.

- High biodiversity and protected surface, the Canary Islands is considered a biodiversity hot spot by the large number of endemic species it contains, it makes a fragile ecosystem, $42 \%$ of the surface of the Canary Islands is protected, in the case of Galapagos Islands the proportion is $95 \%$ of the territory.

- Low level of industrialization. The shortage of materials and higher freight costs for input and output from the island it makes unfeasible, except in cases of products with very high added value or tax exempt.

- Normally the isles have a self-sufficient economies and low population density, in others cases the economy relies heavily on tourism, like Hawaii, the Cayman Islands...

- Shortage of grounds. These small lands, where territorial planning is fundamental, it is desirable that energy installations are as compact as possible and compatible with other land uses.

- High dependence on outside sources for many types of goods and resources, including energy. This phenomenon should be reduced by enhancing the use of endogenous resources. In many cases these resources have a marked seasonality, which requires significant storage systems. In the Canary Islands the two major energy resources are maximum in summer, both sun and wind. Reduce energy dependence should not increase food dependency, so we need to protect the fertile lands from photovoltaic farms and others energy infrastructure. However there are some islands with enough energy resources like large waterfalls (Madeira) or geothermal energy (Iceland, Pantelleria). In many other cases the energy dependence is apparent (Chipre, Greenland, Malta...). It's expensive and increases the risk of shortages, It's very strange an isle with energy self-sufficiency, normally a little ones, like El Hierro, Eigg... The European rule set that by each member country have to get a fuel storage equivalent to 90 days of consumption, in Canary Islands took the same level, the reason was our distance from the rest of our country mainland.

- A system of transport and communications with the outside of high reliability, for example ports for the landing of ships with fuel, we can not rely solely on a simple download by buoys where a temporarily unable would create a big problem.

- The more used size of energy technologies have been thought for mainland, so island scale requires its own designs, more expensive.

- The stability of electricity networks. On the continent are characterized by highly interconnected, which increases the stability and security of the systems, facilitating the integration of renewable energy, like pendulum wind turbine [14].

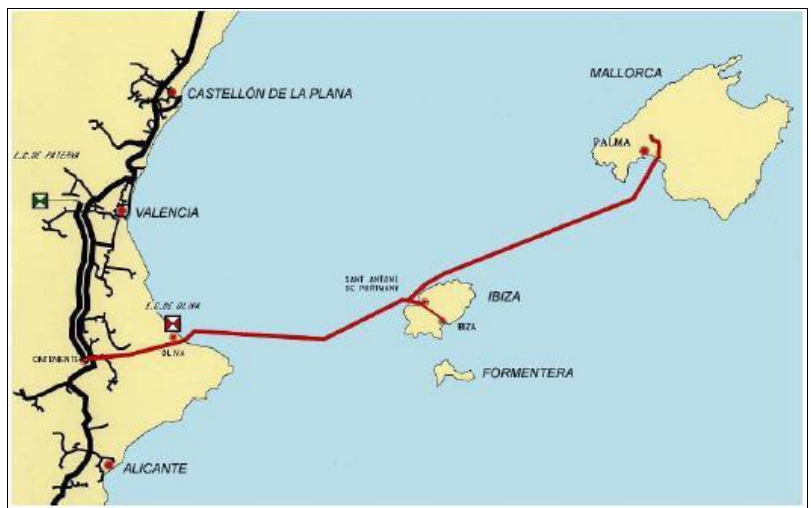

Figure 1. Future Submarine Gas pipeline, and wire.

- Small island systems should explore the feasibility of interconnection with the mainland or among them by electric wires or gas pipelines or other energy transmission system, so please provide the bathymetry of the archipelago. In the case of the project in Balearic Islands have joined the mainland through an undersea cable and gas pipeline.

- Low diversification of energy mix, as well as in the Galapagos Islands for over $95 \%$ of primary energy is petrol, in Greenland 100\% come from fossil fuels. 


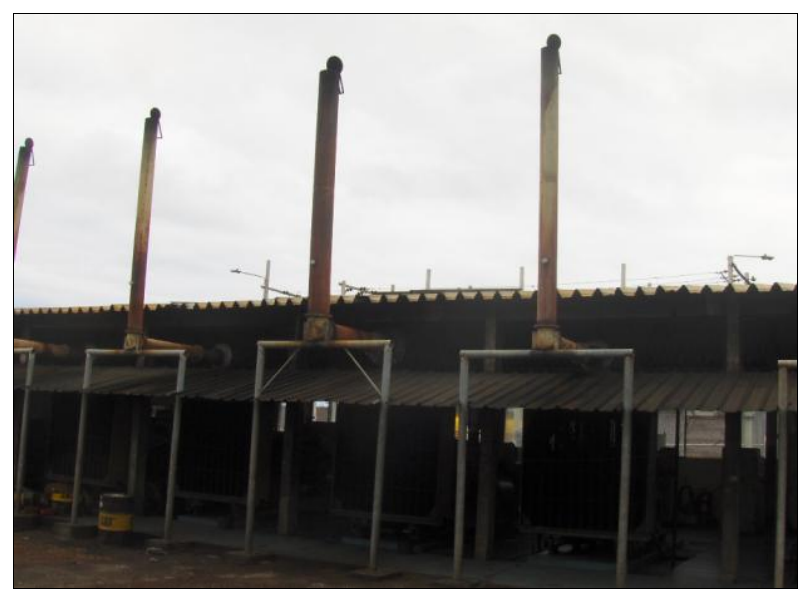

Figure 2. Power Plan in Santa Cruz Isle. Galapagos

\section{Explanation and justification of the methodology}

The methodology followed to achieve the management model presented in this document is as follows.

First we collected all the necessary information. Later we will make a diagnosis of the areas suitable for each technology. All these areas will be studied depth: technologic, environmental and territorially. With them will be a series of alternatives that will result after weighing the proposal to management.

As a result of the process described arise Special Territorial Plan for Energy Infrastructures in an Isle, advance phase.

After the document stays in public information, we will get reports and suggestions, which once collected and studied will be answered and will produce changes to be included in the initial approval stage.

Then again be subjected to public opinion and allegations stated. In the case of the Canary Islands, If we want that these Plans are binding and not merely the recommendation, it must be collected within the Island Plan of the Territory as a development of that sector. We are going to explain the elaboration process.

\section{Information document}

\section{A. Technology}

We collect information from all energy infrastructures and support to, existing on the isle. The configuration, features and capacity; now and approved modifications in the near future. In each technology, we do a report of its interlocking with the surrounding territory, relations with other infrastructure, consumption points ...

Also we look for information about different production technologies, energy storage and energy transport, medium-term trends, and the criteria for implementation of each, considering its possible extension to the island and weight might have on its energy system.

As is known by all sources of electricity generation more developed, not only in Spain but around the world are the conventional energy, onshore wind energy and photovoltaic.
Which are the only set within the zoning map of this Plan. Nevertheless, we analyzed other energy sources, either way leaving the door open for using new technologies always achieve the necessary approvals for implementation. We comment very briefly developed:

- Offshore wind: it presents implementation difficulties because they have no management authority of this document, as it corresponds only to the Central Government to grant these concessions. Besides the lack of offshore platform in the islands, environmentally sensitive report prepared by the Ministry of Environment that advises zones and facilities a minimum distance of 8 $\mathrm{km}$ from the coast to minimize the visual impact. And the Royal Decree 1028/2007 which dictates that the minimum size for these parks are $50 \mathrm{MW}$. It gets difficult in the short term the implementation of these facilities in the Canaries Island.

- Solar Thermal Power, with a large current development in Andalusia, this installations need for a long flat surface, discouraged their introduction in a terrain so rugged and heavily restricted, we have a very short fields for this applications.

- Biomass. The dependence on food from outside the island and the scarcity of fertile fields discourages the relevant conduct energy crops. It emphasizes the cultivation of microalgae as an energy source for their high interest in an area with as much solar radiation, more specifically Spain and Alicante and the Balearic Islands have planned developments in this regard.

- Wave energy. The wave energy to be part of highly variable and unstable, it is in a completely experimental stage, the Spanish facilities in prototype stage are encountering many difficulties. In any case their contribution would be anecdotal in the medium time.

We have two buoys that provide us with the resource values belonging to the State Ports.

The Cantabrian sea has more potential energy than us.

- Geothermal. Unknown high-temperature deposits with which to count the islands in the ground, a foreign company is conducting studies on La Palma and Tenerife, but is told today with results and previous studies that cast unflattering data.

- Hydropower. The islands haven't large continuous water courses to get a significant advantage of these features, the only focus of this nature is found in the island of La Palma "El Mulato", there are a few microhydroelectric in others islands.

- Use energy waste or sewage sludge. The facilities of this kind will disappear in the medium term, generate waste to burn it is absurd, in any form volumes that are managed on the island and the high consumption of these facilities do not provide a relevant contribution to the island's energy basket. Besides the analysis of residues referred to another plan, where not only values the solution, but another type of use probably more interesting, as it could be made into compost.

- Analyzed the energy storage systems. Within the zoning included only deposits of fossil fuels, hydrogen production and pumped storage lidroelectricity. Other storage systems were analyzed but are not included in the plan of management, not to require a significant occupation of land, be compatible with other uses. 
- The high-power batteries and electrochemical capacity have undergone a tremendous development in recent years, the most used are the sodium sulfur batteries and Vanadium redox, have business models with outputs of the order of MW and high storage capacity, would be located on the same production sites or electric substations, not requiring planning.

- The storage of compressed air in underground cavities, we know about geological formations of this kind in the islands, for example volcanic tubes, but we have no geological studies for use it.

- Distributed storage consisting of vehicles for land transportation, the future involves whether electric vehicles or hybrid marketing in Spain is expected in 2010 and they will replace the old fuel powered cars.

- We also analyze the energy transport systems. High voltage lines, gas and oil pipelines. It is concluded that a significant increase penetration unmanaged energies, wind and solar, it necessary to reinforce the transmission system so that it can absorb rapid fluctuations in the flow of power they produce.

\section{B. Energy resources}

We got the information available for each of the energy resources in each islands. This also provides of wind and solar maps. Lanzarote is making a map of waves. We study what about other isles, for example [10]-[13].

We look for possible energy storage installations, like pumped hydroelectric.

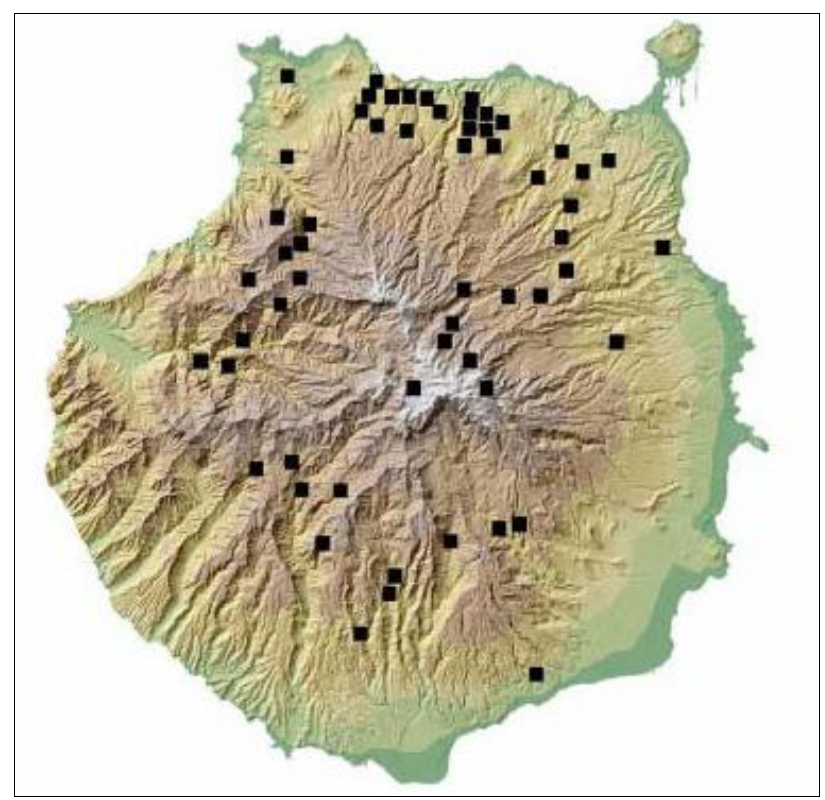

Figure 3 Big dams in Gran Canaria Island. Spain

\section{A. Environmental, Territorial issues}

We analyzed all the information from each of the means of the island, biotic and abiotic, social, economic, patrimony $\ldots$ and this value toward the next stage of diagnosis, ruling out locations where their values could be damaged by proposed actions.

It reviewed all the spatial planning approved or pending of the island, so the following Plans were consulted:
Hydrological Plan, Waste Plan, Tourism Plan and Territorial Plan.

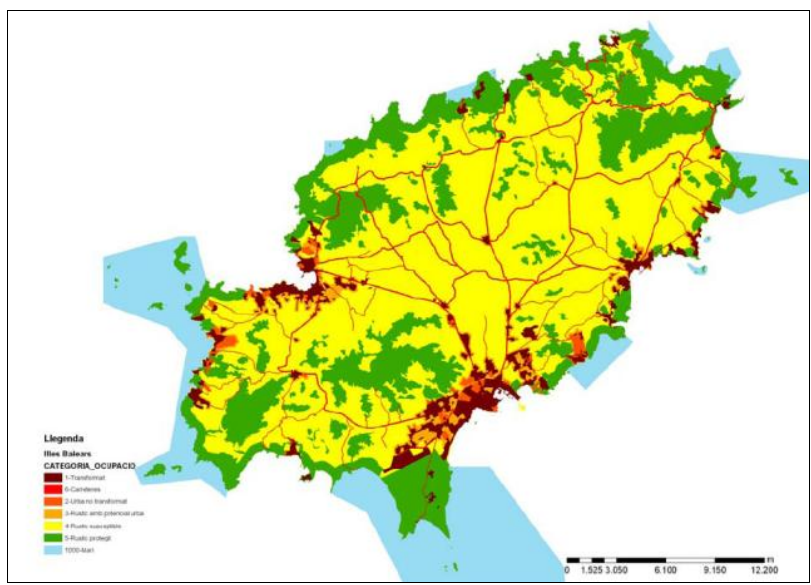

Figure 4. Protected areas in Ibiza Island, in green

\section{B. Calculation of future energy demand}

We performed the estimation of energy demand of the island within the Plan, that is until 2025, which were consulted for updated data on consumption and peak demand, and all projections made by the various groups. Also introduced the possible effects of Climate Change and the other Plans on demand. This reflects that in some islands is by train and tram implemented, in others the water table is very low and the outlook for these latitudes is a decrease in precipitation, so that electricity demand will increase the need for plants desalination. The water cycle on an island like La Palma does not require desalination have good wells and galleries are estimated at $20 \%$ of the global electricity consumption.

\section{Rules}

We studied all legislation affecting such facilities, and plans or goals to accomplish, and directives. Note that our guide was at all times PECAN 2006, or Canaries Energy Plan, which set targets to meet.

This Plan is concern by Planning Territorial rules, energy rules, environment rules, and others, some of then [2]-[9]. For example [5] is about waste incineration to produce energy.

\section{Establish the infrastructure hierarchy}

We fix a hierarchy of energy installations in three levels, the first are the condition for their relevance and should be fully determined its position, the second are those that by their condition should restrict its scope of implementation, then create a zoning, outside it may not take place, and the third by smaller size is widely distributed around all the territory. Depending of the kind of technology and the size the installation were first, second or third level.

Once achieved and ordered all the information was passed to the next stage. 


\section{Diagnosis Phase}

\section{A. The three filters}

In this phase, first we established criteria for each technology implementation using three filters.

- The first filter is the resource or technology restriction, logically if not in a windy location, the rest don't matter.

- The second filter was considered the environmental consideration and protected heritage of each of the areas, ruling out the use of ENPS (protecte area), as well as sites listed in the Natura 2000 and EU directives on habitats and birds.

- The third filter was Territorial issues, where those sites where people were located or their expansion, tourism developments and other classifications incompatible with the use of study.

\section{B. $\quad$ Site selection criteria}

Complicated matter to establish criteria for identifying suitable sites for each technology, as stated above shall be divided into three: technical, environmental and territorial. Once embodied all three filters are overlapping and the intersection will ultimately give us suitable sites. For example see the technical criteria for the siting of power stations. The deploy them near the coast and allow to cool groups using seawater, increasing performance. Although there are groups air-condenser, less efficient, like the new Central of Mallorca isle is, located inland, while natural gas is fed. Additionally inland introduce this facility increases the potential for ground or underground water contamination by accidental leakage of fuel, fuel supply complicates this installation.

If we also want to reduce transportation losses should be located near the centre of the island consumption.

Select a no speep place restricts the slope to avoid large movements of earth, although this restriction has had to raise on the island of La Gomera, because the alternatives involves creating new vehicle accesses with greater impact. In this case has been assessed positively the vicinity of a complex environment with high advantages by grouping annoy instalations.

Do not forget that a thermal power plant involves the movement from port of equipment large tonnage high.

Today the normaly technology in island systems are diesel, medium systems is already a gas turbine for the tips, and only in the largest combined cycle.

So today all Power Stations of the Canary islands are low level, always less than $15 \mathrm{~m}$ on sea level, walking distance to the sea less than $30 \mathrm{~m}$ and in most cases near the entrance port for fuel, most of cases are close to the park store fuel island.

In any case precludes their continued transport of fuel tanker on the road island to supply the stations. For the high risk involved.

The report realiced by REE Spain following the consequences had the storm Delta over the Canary Islands, advises setting up two thermal power plants in the smaller islands and three in the capital isles, in order to improve the reliability of system.[1]
A lot of little village around shore with persons thinking new power station are necesary but No In My Back Yard. For example in the case of own resource energy is positively valued the proximity of high voltage network, but not as important condition because it was felt that if the appeal is important, we look for way to evacuate it, another case is when the area is surrounded by fields of very high natural value.

\section{Specific Scope}

With the resulting lands for each technology, they enlarged the scale of study and prepares a file for each one of the areas, they reflect summarizes the advantages and disadvantages of each area in detail about implementing the technology in question, characterizing all parameters, accompanied by an orthophoto and map it.

In this phase to expand the scale could be reconsidered and ruled out or cut some sparsely populated area to have constraints or other previously uncollected restrict their use.

With the files they had a sufficiently precise information to them and the capacity required to develop the alternatives facing the last phase of management. The language should be simple for non-experts to compare the different areas.

\section{Rules document}

We must to establish a coherent set of alternatives including zero, non-development of the plan. It sets out criteria for assessing each criteria including economic, environmental, territorial, risks and strengths of the model. Based on these, we cross the different alternatives to get the model chosen.

We found conflicting criteria where it is not easy to find the optimal in one side we have the environmentally and economically so the best is all infrastructures together, or near, so the roads and the port is shared, and the surface annoyed is smaller. In the other side we have natural risks like extreme weather, as the Delta storm that devastated Islands, a landslide or an incident at a facility could knock out several of them, clearly separating the actions we reduce hazards.

There has been a regulatory scheme where each technology to provide restrictions on deployment.

There has been a report of environmental sustainability because the national rules force it, it's valued conditions of the Plan, and identifies mitigation, corrective and compensatory measures to consider.

Within the same has been valued contribution to Climate Change Plan and the CC to affect conditions of the Plan, for example, by increasing the average temperature will produce a reduction in the performance of conventional generation, coupled with increased demand for air conditioning needs.

Electricity generation in Canary are subsidy as in most of the islands, it's not a desirable business and the implementation of the Plan will be attributable to private investors, since the energy market is liberalized in Spain, if you put too many restrictions can dispel the money. 


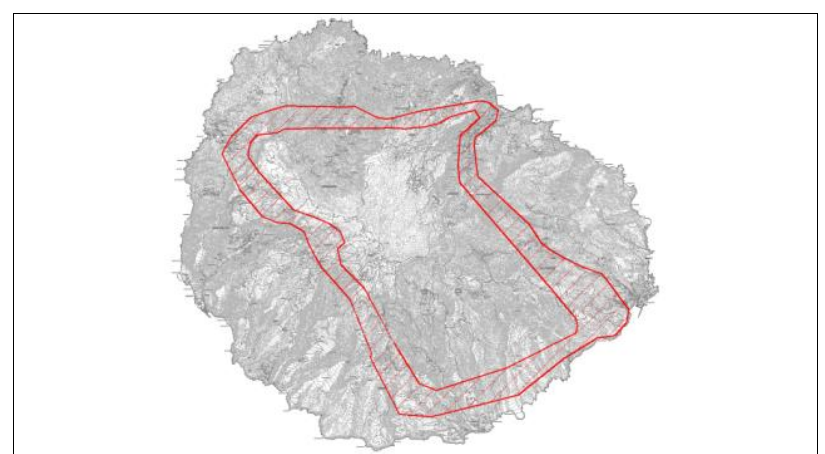

Figure 5. Future zone to AT power line in La Gomera

\section{Phase Public Information}

After leaving public information led to a series of reports and suggestions, which once collected and studied, were answered and led to changes that are included in this initial approval stage.

We have encountered problems of NIMBY for installations considered annoying, so the introduction of natural gas is delayed a decade by the strong popular opposition. Just the opposite is true for plants with high economic premium, whether eolic or photovoltaic, and many people asked that their plots are allowed.

In general people and organizations are demanding the burying of the electric lines which increases and complicates their management, especially in islands with steep terrain.

We met with corporations seeking a place for facilities, but everywhere are protected areas, because never before anybody has been contemplated energy infrastructures, the old territorial plans did "all non-agricultural or urban lands was protected", without other considerations. In many islands Power Plant which had been built on the outskirts in the past. Now is within the city, not easy to find a different site that satisfies everyone.

\section{Conclusions}

Island systems rely on themselves, equipment and systems requires smaller, more capable of regulation is necessary to reduce its external dependence using all their own energy resources and putting storage devices. We need to increase diversity and reduce the risk.

Isles are small areas and usually with more biodiversity, which makes them more fragile.

They should have specific strategies to set their energy needs.

\section{References}

[1 Vulnerabilidad de los sistemas eléctricos aislados . INFORME No. 1 FECHA: 12/12/2007 EDIC. 1. REE

[2] Ley 9/2006, de 28 de abril, sobre evaluación de los efectos de determinados planes y programas en el medio ambiente,(B.O.E. $n^{\circ}$ 102, de 29.4.06)

[3] Ley mediante el Reglamento de Procedimientos de los instrumentos de ordenación del sistema de planeamiento de Canarias, aprobado por Decreto 55/2006, de 9 de mayo (B.O.C. $\mathrm{n}^{\mathrm{o}} 104$, de 31.5.06).
[4] Leyes de Ordenación del Territorio de Canarias y de Espacios Naturales de Canarias, aprobado mediante Decreto Legislativo 1/2000, de 8 de mayo (B.O.C. ${ }^{\circ} 60$, de 15.5.00) [5] DIRECTIVA 2006/12/CE DEL PARLAMENTO EUROPEO Y DEL CONSEJO de junio 2008, relativa a los residuos

[6] REAL DECRETO 1578/2008, de 26 de septiembre, de retribución de la actividad de producción de energía eléctrica mediante tecnología solar fotovoltaica

[8] BirdLife International. Birds and Habitats Directive Task Force. Position Statement on Wind Farms and Birds. Adopted on 9 December 2005

[9] Directrices para la evaluación del impacto de los parques eólicos en aves y murciélagos. Seo birdlife. Depósito legal: M3341-2009

[10]Pantelleria Island, A Global Strategy For Res Integration And Energy Sustainability. G. Tondi. 19th European Photovoltaic Solar Energy Conference, 7-11 June 2004, Paris.

[11] Energy Efficient System for St Martin's Island ofBangladesh. M. Sliamim Kaiser and S.K. Aditya. Journal ofEngineering andApplied Sciences 1 (2): 93-97, 2006

[12] Increasing Renewable Energy Generation Increasing Renewable Energy Generation on an Isolated Island Grid on an Isolated Island Grid. Dan V. Giovanni. 23rd Pacific Islands Environmental Conference Saipan, CNMI June 21-25, 2004

[13] Optimal configuration of island's energy supply system. Sandrina Pereira, et all. Chemical Engineering Transactions Volume 18, 2009 Editor J ¡Fí Klemes Copyright (C) 2009, AIDIC Servizi S.r.1., ISBN 978-88-95608-04-4 ISSN 19749791 D01: 10.3303/CET09181 02

[14] http://www.ades.tv/proyectos/pendular-wind-turbine 